\section{Effect of Strategic Management on Organisational Learning: Evidence from the Banking Sector in Nigeria}

Worimegbe Powel Maxwell

Adelekan Adedeji Saidi

Eze Benneth Uchenna
Kardan Journal of Economics and Management Sciences

3 (4) 41-71

(c)2020 Kardan University Kardan Publications

Kabul, Afghanistan

https://kardan.edu.af/Research/

CurrentIssue.aspx?j=KJEMS

\begin{abstract}
The study examines strategic management dimensions on Organisational learning in the banking sector with the aim of establishing the most significant construct driving organizational learning. The study is premised on the strategic implementation and strategic analysis dimensions of strategic management. The survey research design was employed in the study. 400 bank employees were surveyed through questionnaires. Data were analyzed using the regression. The result reveals that the elements of strategic management $(B=0.788, R 2=0.621$, $F=56.733, p=0.000$ ) combined have a significant effect on organizational learning. The study also established that strategic implementation is the most significant driver of organizational learning in the banking sector. The study was carried out in the banking sector. It is expected that the outcome may vary if such study is carried out in other industry and climate. The study shows that organisations especially those in the banking sector should place more attention to the implementation of their strategic goals as they continually analyse their internal and external environment as this will drive them to better performance. They should align their strategies with the dynamic environment in order to achieve their corporate goals. The study addresses the issue of strategic management as it drives organizational learning.
\end{abstract}

Keywords: Strategic Analysis, Strategic Implementation, Management, Learning Organization

JEL Classification Code: M129

Mr. Worimegbe Powel Maxwell Department of Business Administration, Faculty of Management and Administration, Olabisi Onabanjo University, Ogun State Nigeria. <powelmaxwell@yahoo.com> Dr. Adelekan Adedeji Saidi is a Senior Lecturer, Department of Business Administration, Faculty of Management and Social Science, Dominican University, Oyo State, Nigeria. selevateddeji2@gmail.com> Dr. Eze Benneth Uchenna, Department of Business Administration, Faculty of Management and Social Sciences, Hallmark University, Ogun State, Nigeria. < beneze7@mail.com> 


\section{Introduction}

Learning is critical in the life of an organisation (Worimegbe, 2020) as the firm as a whole will be improved by the emergence, retention and transfer of information within the organisation. An innovation or product is created, and the idea or product is generated by the organisation when learning occurs through, thereby leading to better performance and competitive advantage (Coban, Ozdemir \& Pisapia, 2019). Besides these, in organisational learning, there are three main processes: knowledge formation, preservation of knowledge, and transfer of knowledge. Organisational learning theory focuses on knowledge formation and the application of that knowledge within an enterprise. Critical aspects of the theory of organisational learning are that when people communicate when discovering and solving problems, learning occurs. The theory of organisational learning emphasises the importance of cultivating a culture of learning within an organisation. However, Soomro, Mangi, and Shah (2020) opine that organisational learning does not happen suddenly but through top executives' systematic yet strategic action. While organisations enjoy organisational learning, it is imperative for such organisations to develop frameworks and strategies which could make them optimise such benefits. Patrick, Moses and Martin (2019) argue that strategic management could impact organisational learning, yet to the best of the researchers' knowledge, there is no empirical evidence supporting such arguments.

Strategic management has stimulated a lot of research interest among scholars across the globe. It aids the discovery, understanding and implementation of a new approach of enhancing organisational learning. This helps firms, especially a learning organisation to develop the ability to learn, confront and envisage new challenges proactively, improve the flexible contributions of the employees, recognised and establish a change adoption mechanism, which tends to breed continuous transformation (Didwania, Unger, Mitra, McGaghie, 2020). In spite of the explosion in the practice of strategic management, particularly the strategic analysis and strategic implementation components of strategic management, it continues to generate argument from researchers. Several scholars (Angsor \& Yusof, 2019; Bazhenov \& Oykher, 2020; Mutuku \& Misango, 2020; Patrick, Moses \& Martin, 2019; Qin, Liu \& Tian, 2020) have studied strategic analysis and strategic implementation from the perspective of Internal factors, logistics, information system, environmental factors and economic potential, among others. However, it seems that no study has examined strategic analysis and strategic implementation from the perspective of 
organisational learning, particularly in the Nigerian banking sector. Furthermore, most of the studies employed only one strategic management component, without considering the combined effect of strategic analysis and strategic implementation on organisation learning. This gap in literature forms the core of this study. The study is significant in two-fold: Firstly, it extends previous studies on strategic management, by examining the combined effect of strategic analysis and strategic implementation on organisational learning. Secondly, the study opens up new research vista on strategic management's broad concept, particularly strategic analysis and strategic implementation. It is important to state that this study's policy implications will be pertinent to the banking sector. The Nigerian banking environment is continuously evolving due to the impact of technology, Globalisation, management dynamics and environment influence (Worimegbe, Abosede \& Worimegebe, 2018). Also, Worimegbe (2020) asserts that the Nigerian banking industry is continuously evolving and that there is a need to continually adapt strategies that could lead to and influence competitive advantage in the long run. This has created a need to investigate how strategic management using strategic analysis and strategic implementation affects learning organisations in the Nigerian banking industry. The motivation for this study is also based on the recommendations of Bowles (2013), who assert that the banking industry is prone to fluctuations caused by top executes strategies. However, the degree of such strategic activities on learning organisation is scarce in existing literature based on the Nigerian context. Thus, the objective of the study is to examine the effect of strategic analysis and strategic implementation on the organisational learning of Nigerian banks.

\section{Literature Review}

\subsection{Strategic Analysis}

Worrall (2011) opines that strategic analysis is the theoretically enhanced evaluation of the dynamic business environment where an organisation exists and how the organisation uses such understanding to interact with the ever-evolving business conversation, in order to increase effectiveness and the efficiency of the organisation, thereby causing an increase in the organisation's potentials to allocate resources optimally. The Chartered Institute of Management Accountants (CIMA, 2005) identified PEST, SWOT analysis, four corner analysis, war game, Porter five forces analysis, early warning scans and value chain analysis as tools for strategic thinking and analysis. A SWOT (strengths, weaknesses, opportunities and threats) analysis tool is widely employed in understanding the capabilities, shortcomings, opportunities and risks inherent in the business environment 
the firm exists in. The organisation's strength looks at what it does better than others, its unique capabilities, customers' and competitors' perception of the organisation's strengths, and what the organisation considers its competitive edge. The weaknesses include but are not limited to what competitors are doing better, the business feature or service delivery that adds no value, what customers and business rivals in the market consider a weakness. The opportunities analysis includes how favourable the changes taking place in the political, economic, social-cultural and technology (PEST) are to the organisation, identifying and recognising the unfulfilled demand and current gaps in the markets and identifying the organisations' creativity and innovation brought to the market. The threat analysis evaluates the political, economic, social-cultural, or technology (PEST) transformations taking place in the market which are unfavourable to the organisation, the constraints in terms of controllable and uncontrollable factors and the negative impacts of the competitors' actions.

The above analysis is the most commonly used in the strategic analysis (Mba, 2007). However, Boulton (2007) opines that using the PEST (Political, Economic, Socio-cultural and Technological) analysis is critical to strategic thinking. PEST analysis as a strategic tool is key to scanning the business environment, categorised as opportunities or threats in SWOT analysis. The Porter five analysis as a strategic analysis tool is important in determining a firm's competitive position. It assesses and evaluates the organisational position and competitive strength. The porter five models determine the competitive attractiveness and intensity of the market. The strategic analysis helps understand how rewarding a strategic move is and helps to strengthen weaknesses and avoid potential mistakes.

\section{Figure 1: Porter Five Strategic Model}

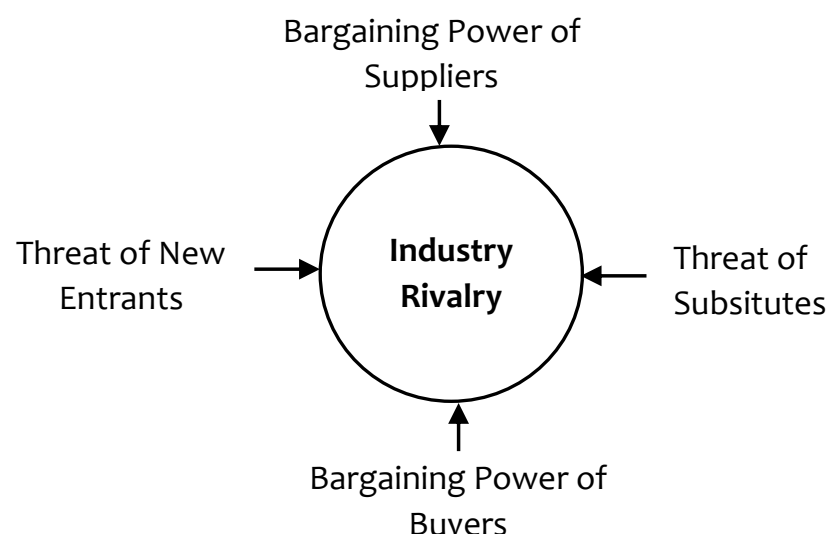

Source: Porter (2008) 
Mba (2007) sees the porter four corner analysis as very important in assisting an organisation's strategists in evaluating and examining competitors' objectives and intent and how such plans are achieved. This tool is vital in determining each competitor likely action to change in the market and the environment. It anticipates potential moves in the market and helps to understand how to react to such movements. However, Comai and Tena (2007) emphasise that for strategies to study, and right strategic decisions to be taken, an organisation must understand how its internal activities create values and that this can be rightly done through value chain analysis. The value chain analysis is premised on the belief that customers are the main reason organisations exists. By evaluating each of its activities, the organisation can effectively determine its internal capabilities and harness them to create superior values.

All the tools investigated for strategic analysis are important. It is imperative to know that for strategies to be successful, there should be a strategic implementation. Strategic implementation is the next step after SWOT analysis, environmental scans, value chain analysis, and recognising strategic goals and issues (Athapaththu, 2016; David, 2011; Lorette, 2018; Mba, 2007; Qin, Liu \& Tian, 2020) and not having a system that could effectively execute formulated strategies could be a great hindrance to strategic analysis since the right implementation gives room for the current situation's current assessment.

\subsection{Strategic Implementation}

Misankova and Kocisova (2014) assert that strategic implementation's main role is to activate the strategy and make it part of the organisation's everyday life and culture. They further posit that strategic implementation is the most underestimated, yet the most pivotal part of strategic management. Strategic implementation is important to the success of the organisation. The effective implementation of an ordinary strategy can beat the second-rate implementation of an excellent strategy". A strategy can be sound yet fail due to implementation (Angsor \& Yusof, 2019; Mutuku \& Misango, 2020; Patrick, Moses \& Martin, 2019; Thompson \& Martin, 2005). David (2011) is of the view that the most difficult part of strategic management is strategic implementation and that for strategic implementation to be effective, the right strategic tools should be used. For effective strategic implementation to occur, the best unique approach which suits the external and internal challenges should be adopted.

In Gavurová's (2010) view for strategic implementation to be effective, there should be strategy communication throughout the organisation, and employees should be involved in the strategy, adopting a structure for the 
organisation and execution of an effective control system. Organisations should align their strategic implementation processes with their structures, and this is achievable through a learning organisation. An organisation has the capacity to survive in the long run, when it successfully aligns structures by self-regulating processes, and this is possible through learning organisation which is determined and self-organised (Luhn, 2016).

\subsection{Learning Organization}

Senge (2011) postulates that a learning organisation is a place where people deploy their capabilities and resources to continuously achieve stated organisational objectives, deploy new ways of doing things and thinking, and develop new deliverable hopes so that the employees and the organisation as a whole will perform effectively. Didwania et al. (2020) believe that a learning organisation can learn, face and envisage new challenges proactively, improve the flexible contributions of the employees, recognise and develop a change adoption mechanism. The learning organisation breeds continuous transformation. In this study, the link between strategy and learning organisation can be seen as interdependent. Learning organisation can be a strategy of the organisation in meeting the challenges of the evolving business environment while an organisation's strategy is to have a learning organisation (Coban, Ozdemir, \& Pisapia, 2019; Soomro, Mangi, \& Shah, 2020). This assumption is premised on Bowles' (2013) works, who established that the best strategic method for achieving organisational objectives and competitiveness is implementing a learning strategy at an organisational or strategic level. An organisation that consistently learns builds strategies that are rare and employs resources effectively to make those strategies a reality, thereby complimenting the organisation's drive for better performance. A learning organisation has the capacity to create disruptive technologies and employ dynamic capabilities by aligning its resources to current realities, thereby achieving its goals. Learning organisation is a strategy which is pivotal to adapting to a dynamic environment.

\subsection{Strategic Management and Learning Organization: The Nexus}

Strategic management has engendered a lot of discussions in the existing literature. Strategic management and its components (strategic analysis and strategic implementation) have been argued to be a driver of financial performance, firms' effectiveness, technological awareness, firm competitiveness and fostering an increase in market share (Soomro, Mangi, \& Shah, 2020, Coban, Ozdemir, \& Pisapia, 2019; Bowles, 2013; Comai \& Tena, 2007). The effect of strategic management on learning organisation has been of concern to scholars in most recent times. Didwania et al. (2020) 
stress that a learning organisation could be enhanced by top management's ability to strategically implement their core values and strength. This opinion was also supported by Bazhenov and Oykher (2020) and Mutuku and Misango (2020) who assert that firms could utilise strategic analysis to achieve their specific targets and goals. It is yet to be revealed how strategic analysis has led to organisational learning and the extent to which strategic analysis has influenced learning organisation. Premised on the aforementioned discussions, it is envisaged that that strategic learning would drive organisational learning. Hence the following hypothesis is formulated:

\section{Hypothesis 1: Strategic analysis has a significant effect on organisational learning in the Nigerian banking sector.}

Gavurová (2010) posits that strategic implementation is based on efficient strategic communication which should take place throughout the organisation, employees should be involved in the plan, adopting an organisational structure and introducing an effective control system. Organisations can match their strategic executions processes with their systems and accomplish their corporate objectives through a learning organisation. An organisation has the ability to succeed in the long term when self-regulating mechanisms effectively align systems, and this is possible through a committed and self-organised learning organisation (Luhn, 2016). However, it is yet to be ascertained how strategic implementation could bring about achieving corporate organisation through a learning organisation. While the studies of Mutuku \& Misango (2020); Patrick, Moses and Martin (2019) reveal the influence of internal factors on strategy implementation and factors affecting strategy implementation among local non-governmental organisations, the effect of strategic implementation on learning organisation is not revealed. Therefore, the second hypothesis is formulated;

\section{H2: Strategic implementation has a significant effect on organisational learning in the Nigerian banking sector}

Angsor \& Yusof (2019) examined the effect of strategic implementation and analysis in the public sector and concluded that it is not enough to look at the effect of these two components of strategic management from a particular sector and reach a conclusion. Bowles (2013) argues that there is a need to determine the combined effect of these dimensions (strategic implementation and strategic analysis) of strategic management in a dynamic environment. This is so because strategic implementation and strategic analysis cannot be done isolation and that both dimensions go and in hand (Worimegbe et al., 2018). Therefore, this study's third hypothesis is 
to establish the impact of strategic analysis and strategic implementation on learning organisations.

H3: Strategic analysis and strategic implementation have combined significant effect on organisational learning in the Nigerian banking sector

\subsection{Environmental Theory}

This study is anchored on the idea that the firm's environment and actions are the major driver learning organisation. These factors enhance and take the role in the strategist. According to Stacy (1993), strategic management's environmental theory is based on the contingency theory of management. Contributors to this theory opine that the firm dies out when it is static to the dynamic environment (Freeman, 1984; Schendel and Hofer, 1979). Strategy is a process, and it deals with experimenting and adjusting to situations that, if not properly handled, will inevitably lead to the firm's collapse. Firms that adapt to the environment survive and attain competitiveness. Strategy integrates human intelligence, imagination, firm resources and coordinated behaviour towards accelerating the rate of change and effecting competition.

The theory is also premised on process formation and developing strategy through an open approach whereby the more powerful and stronger influence drives the overall strategy creation and implementation. McKiernan (2015) is of the opinion that in formulating a strategy, the organisational culture plays a pivotal role and this; the classical theory integrates into the implementation of the strategy. Culture becomes the greater influence driving soul of the organisation. The organisational strategy depends immensely on how robust and adept its culture is.

The theory is adopted in this study because it is expected that strategic management which is a function of the environment, would lead to organisational learning.

\subsection{Conceptual Framework}

Figure 2: The Link between Strategic Management and Learning Organization

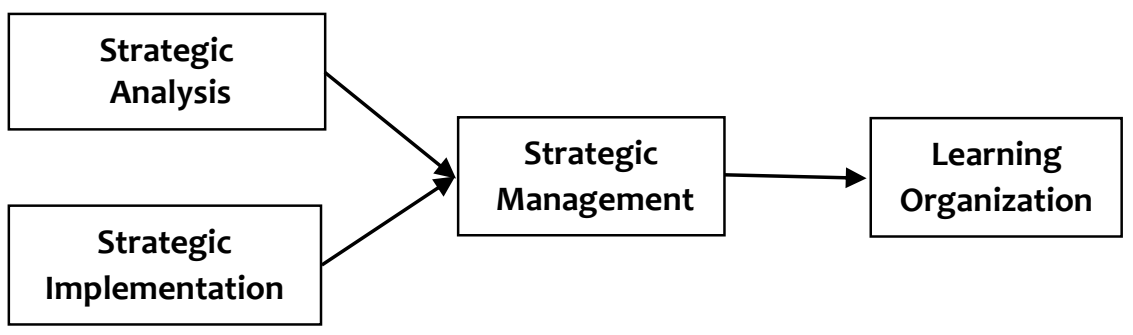

Source: Authors (2020) 
Figure 2 shows the interaction between strategic management and learning organisation. In the $A^{\prime}$ priori expectation, it is envisaged that strategic management and its components would have a positive influence on learning organisation.

\section{Research Methodology}

This study employs a survey research design in accessing information from the banking industry in Nigeria. The banking industry has a total number of 104,669 employees, according to the Nigerian Bureau of Statistics (NBS, 2019) is 104,669. However, Hair, Anderson, Tatham \& Black (2010) suggest that, where the sample size exceeds 400 , the goodness of fit is poor because almost any difference is detected. Therefore, by considering the constraints of the research setting and theoretical aspect of this study, the targeted sample size was purposively set at $400 \quad(n=400)$. The questionnaire was distributed equally among the three categories (international, national and regional) of banks employees in Nigeria with the aid of research assistants. The study was carried out in Lagos State, Nigeria. The choice of Lagos was influenced by the fact that it has the highest number of deposit money branches, and all the banks have their corporate headquarters located there. The deposit money banks in focus are heterogeneous and to ensure adequate representations, employees were taken from each of the 20 deposit money banks selected.

\subsection{Instrumentation and Operationalisation of Variables}

A well-structured questionnaire comprising of 22 measured items for strategic management grouped into strategic analysis and strategic implementation was adopted from the studies of McKiernan (2015) and Bowles (2013) while 15 items measures adopted from the studies of Coban, Ozdemir, and Pisapia (2019) and Soomro, Mangi, and Shah, (2020) were used for organisational learning grouped into learning culture, information sharing and experience. Data were analysed using the statistical regression tool. 329 (82.25\%) questionnaires were properly filled and returned. These were considered sufficient for analysis based on the recommendations of Hair et al. (2018). The result of the first and second pilot tests was correlated. A Cronbach alpha of $\alpha=0.783,0.843$, and 0.841 was achieved for the organisational learning constructs, strategic analysis and strategic implementation construct respectively.

Table 1: Psychometric Properties of the Scale

\begin{tabular}{lll}
\hline Measurements & Cronbach Alpha & Average Variance Extracted \\
\hline Strategic Management & 0.822 & 0.715 \\
Strategic Analysis & 0.765 & 0.635 \\
Strategic Implementation & 0.865 & 0.721 \\
\hline
\end{tabular}




\begin{tabular}{lll}
\hline Learning Organization & 0.841 & 0.716 \\
Learning culture & 0.806 & 0.694 \\
Information sharing & 0.873 & 0.727 \\
Experience & 0.789 & 0.653 \\
\hline
\end{tabular}

Source: Authors Computation, Field Analysis (2020)

The psychometric properties of the scale were evaluated using the Confirmatory Factor Analysis in Table 1 (CFA). In the model, all variables were checked, and the loading of items was limited to the parameters set by Fornell and Larcker (1981). That is, $>0.5$ was the ability to calculate the latent variables and the scale's internal consistency. For all latent variables, the findings show a high indication of average variance and construct reliability. Validity and construction were assured. In obtaining internal consistency, by following the tool used by previous studies and using the CFA to ensure construct validity, the researchers ensured that the instrument measured what it was supposed to measure.

\subsection{Model Specification}

The theory underpinning the model for this study is the environmental theory based on the studies of McKiernan (2015) and Bowles (2013), which employed both constructs, respectively. Strategic thinking and strategic implementation as a direct antecedent of organisational learning follow:

Organizational Learning

$=\beta_{0}+\beta_{1}$ (Analysis)

$+\beta_{2}$ (Strategic Implementation)

$\beta o$ is the constant

$\beta_{1}, \beta_{2}$, are the coefficient estimators

$\mu$ is the error term

From the above discussion, it is expected that strategic thinking and strategic implementation will exhibit a positive relationship with organisational learning. Hence there will be a directly proportionate relationship strategic thinking and strategic implementation on organisational learning.

\subsection{Findings and Discussion}

Table 2: H1. Strategic analysis has a significant effect on organisational learning in the Nigerian banking sector

\begin{tabular}{llllll}
\hline & \multicolumn{5}{c}{ Organizational Learning } \\
Variable & $\mathrm{B}$ & $\mathrm{SE}$ & $\mathrm{B}$ & T-Value & P-Value \\
\hline Strategic & 0.310 & 0.020 & 0.371 & 18.553 & 0.000 \\
Analysis & & & & & \\
$\mathrm{R}^{2}$ & 0.086 & & & & \\
Collinearity & 1.055 & & & & \\
\hline
\end{tabular}

Source: Authors Computation, Field Analysis (2020) 
The result from table 2 reveals that there is a positive but significant relationship $(\beta=0.371)$ between strategic analysis and organisational learning. The coefficient of determination $\left(R^{2}=0.086\right)$ reveals that $8.6 \%$ variation in organisational learning is explained by strategic analysis. The unstandardised coefficient $(B=0.310)$ shows that for every unit increase in strategic analysis, organisational learning increases by 0.310 units. The $t$ value ( $t$-value $=18.553, p=0.000$ ) establishes that strategic analysis is $a$ significant predictor of organisational learning. Therefore, the null hypothesis is rejected while the alternative hypothesis is accepted.

Table 3: H2. Strategic implementation has a significant effect on organisational learning in the Nigerian banking sector

\begin{tabular}{llllll}
\hline & \multicolumn{5}{c}{ Organizational Learning } \\
Variable & $\mathrm{B}$ & $\mathrm{SE}$ & $\mathrm{B}$ & T-Value & P-Value \\
\hline Strategic & -0.625 & 0.158 & -0.649 & 4.113 & 0.000 \\
Implementation & & & & \\
$\mathrm{R}^{2}$ & 0.421 & & & \\
Collinearity & 1.013 & & & & \\
\hline
\end{tabular}

Source: Authors Computation, Field Analysis (2020)

The result from table 3 reveals that there is an inverse but significant relationship $(\beta=-0.649)$ between strategic implementation and organisational learning. This indicates that as strategic implementation reduces, organisational learning increases. The coefficient of determination $\left(R^{2}=0.421\right)$ reveals that $42.1 \%$ variation in organisational learning is explained by the strategic implementation. The unstandardised coefficient ( $B=-0.625$ ) shows that for every unit increase in strategic implementation, organisational learning decreases by 0.625 units. The $t$ value ( $t$-value $=4.113$, $\mathrm{p}=0.000$ ) establishes that strategic implementation is a significant predictor of organizational learning. Therefore, the null hypothesis is rejected while the alternative hypothesis is accepted.

Table 4: H3. Strategic analysis and implementation have combined significant effect on organisational learning in the Nigerian banking sector

\begin{tabular}{llllll}
\hline & \multicolumn{5}{c}{ Organizational Learning } \\
Variable & $\mathrm{B}$ & $\mathrm{SE}$ & $\mathrm{B}$ & $\mathrm{T}$-Value & P Value \\
\hline Strategic & 0.765 & 0.044 & 0.788 & 18.326 & 0.000 \\
Analysis and & & & & \\
Implantation & & & & \\
$\mathrm{R}^{2}$ & 0.621 & & & \\
Collinearity & 1.058 & & & \\
F-stat & 56.733, & & & \\
& $\mathrm{p}=0.000$ & & & & \\
\hline
\end{tabular}

Source: Authors Computation, Field Analysis (2020) 
The result from table 4 reveals that there is a positive and significant relationship $(\beta=0.788)$ between strategic analysis and implementation combined and organisational learning. This implies that when strategic analysis and implementation are jointly utilised organisational learning increases in the banking sector. The coefficient of determination $\left(R^{2}=0.621\right)$ reveals that $62.1 \%$ variation in organisational learning is explained by the joint utilisation of strategic analysis and implementation. The unstandardised coefficient $(B=0.765)$ shows that for every unity increase in strategic analysis and implementation, organisational learning increases by 0.765 units. The F-Stat $(F=56.733, p=0.000)$ establishes that strategic analysis and implementation have a combined effect on organisational learning. Therefore, the null hypothesis is rejected while the alternative hypothesis is accepted.

\section{Discussion of Results}

The findings from the study show the importance of strategic analysis to the learning organisation. The result reveals that there are strategic analysis influences learning organisation, but it is causing a low variation on learning organisation. This corroborates the positions of Beer, Lei bold, Voelpel and Tekie (2005) who envisaged that strategic analysis could stimulate the capacity of an organisation to learn and fit into the dynamic environment. It is inferred from this that, an in-depth analysis of the internal and external environment should be done for a firm better performance. Strategic implementation has a significant relationship with the learning organisation. This is very pivotal to an organisation's success. The findings of the results indicate that strategic implementation is activated the strategy that makes learning an important part of the organisation's everyday life and culture. This consistent with the study of Bowles (2013), who established that the best strategic method for achieving organisational objectives and competitiveness is implementing a learning strategy at a managerial or strategic level.

The result of the combined effect of strategic analysis and strategic implementation, which are dimensions of strategic management on learning organisation reveals that a firm should jointly employ these dimensions in order to be better placed to learning. The joint utilisations of these strategies will make an organisation perform effectively, and align itself with its capabilities, environment and operations. The findings are consistent with the positions of Mutuku \& Misango (2020); Patrick, Moses and Martin (2019); Angsor \& Yusof (2019) and Bowles (2013) who confirmed that strategic management is instrumental to firm competitiveness and performance. Although these studies are in tandem to the findings of this 
study, this study establishes that there is a linking between the environment which is a driver of strategic management (strategic analysis and strategic implication) and organisational learning.

\section{Practical Implication}

The study reveals the interaction between the components of strategic management (Strategic analysis and strategic thinking) and learning organisation. The implication of this is that the more a firm increases its capacity to strategic analysis its operations in relations to its resources and strategical implements its plans and decisions, the more it fosters its capacity to learning more thereby leading to competitive advantage. It is not enough for a firm to have a strategy, there is an effective need to properly analysis and implement such strategies in achieving its corporate goals.

\section{Conclusion}

The study looks into how the dimensions of strategic management drive organisational learning in the banking sector. The study concludes that strategic management dimensions (strategic analysis and strategic implementations) are predictors of organisational learning. The study also concludes that both dimensions should be jointly employed by an organisation in order to be better placed for learning. The study recommends that organisations, especially those in the banking sector, should place more attention in the analysis of their internal and external environment as this will drive them to better performance. They should align their strategies with a dynamic environment in order to achieve their corporate goals.

\section{Recommendations for Further Studies}

The study recommends that future studies should examine the impact of strategic management using other forms of performance measures in the financial sector as a whole. Other components of strategic management should also be utilised in determining how strategic management interact with other dimensions of performance.

\section{References}

Angsor, S., \& Yusof, M. M. (2019). Practising and factors influencing the effective implementation of strategic information systems planning in public agency. UKM Journal of Management, 56(1).

Athapaththu, H.K.S (2016). An overview of strategic management: an analysis of the concepts and the importance of strategic management. International Journal of Scientific and Research Publications, 6, (2), 124-133 
Bazhenov, O., \& Oykher, A. (2020, April). Strategic analysis of environmental and economic potential of Norilsk metallurgical cluster. In E3S Web of Conferences, 161, 01022.

Boulton, W.R. (2001). Understanding the strategic analysis model.

Bowles, M (2013). Lead learning strategy implementation. Institute for Working Futures.

CIMA (2007). Strategic Analysis Tools.

Comai, A. and Tena, J. (2007). Early warning systems for your competitive landscape. Society of Competitive Intelligence Professionals, 10, -43

Coban, O., Ozdemir, S., \& Pisapia, J. (2019). Top managers' organisational change management capacity and their strategic leadership levels at Ministry of National Education (Money). Eurasian Journal of Educational Research, 19(81), 129-146.

Didwania, A. K., Unger, E. D., Mitra, D. L., \& McGaghie, W. C. (2020). Mastery learning of team skills. In comprehensive healthcare simulation: Mastery learning in health professions education. Springer Cham.

David, F. R. (2011). Strategic Management Concept and Cases, 13th ed. Florence, South California: Pearson Education Limited, 2011.

Freeman, R. E. (1984). Strategic management: a stakeholder approach. Boston: Pitman

Gavurová, B. (2010) Meranievýkonnosti v organizaciach s dorazomnaaplikaciusystemu Balanced Scorecard.Kosice: Technickauniverzita v Kosiciach. Harvard Business Review, 86(1), 78-93.

Hair, J., Black, W., Babin, B. and Anderson, R. (2010). Multivariate Data Analysis. Upper Saddle River, NJ: Prentice-Hall.

Lorette; k. (2018). What is Strategic Implementation?

Luhn, A. (2016). The Learning Organization. The Gruyter Open. 1(3), 1-23

Mba (2007). Porter'sfive forces. www.quickmba.com/strategy/porter.shtm [Accessed 12 February 2020]

McKiernan, P. (2015). Historical Evolution of Strategic Management, Vol.6.Aldershot: Dartmouth.

Misankova, M. \&Kocisova, K. (2014). Strategic Implementation as a Part of Strategic Management.Procedia - Social and Behavioral Sciences 110 (2014) 861 - 870

Mutuku, L., \& Misango, S. (2020). Influence of internal factors on strategy implementation in Machakos County Government, Kenya. European Journal of Business and Strategic Management, 5(1), 37-54.

Patrick, M., Moses, M., \& Martin, K. (2019). Factors affecting strategy implementation among local non-governmental organisations in Kenya: A survey of NGOs in Nairobi County. International Journal of Business Management and Finance, 1(1).

Porter, M. E. (2008). The five competitive forces that shape strategy. Harvard Business Review, 86(1), 78-93.

Qin, X., Liu, Z., \& Tian, L. (2020). The strategic analysis of logistics service sharing in an e-commerce platform. Omega, 92, 102153.

Stacey, R. (1993). Strateškimenadžmentiorganizacijskadinamika. Zagreb: Mate 
Schendel DE, Hofer CW (eds). 1979. Strategic Management: A New View of Business Policy and Planning. Little, Brown: Boston, MA.

Senge, P. M. (2011): Die fünfteDisziplin, 11., völligüberarbeitete und aktualisierteAufl., Stuttgart: Schäffer-PoeschelVerlag.

Soomro, B. A., Mangi, S., \& Shah, N. (2020). Strategic factors and significance of organisational innovation and organisational learning in organisational performance. European Journal of Innovation Management.

Thompson J. and Martin, F (2005). Strategic Management, 5th ed. London: Thompson,

Worimegbe, P. M. (2020). Coopetition and customers' experience in the Nigerian banking sector: The moderating effect of technology. Global Journal of Business, Economics and Management, 10(2), 111-123.

Worimegbe, P. M., Adebiyi, A.J. \& Worimegbe, T.M (2018). Efficiency, customers' Satisfaction and deposit money banks' performance in Nigeria. Journal of Economics and Management, 31(1), 134-145, 